This item was submitted to Loughborough's Research Repository by the author.

Items in Figshare are protected by copyright, with all rights reserved, unless otherwise indicated.

\title{
Data sharing in crime prevention: why and how
}

PLEASE CITE THE PUBLISHED VERSION

VERSION

VoR (Version of Record)

LICENCE

CC BY-NC-ND 4.0

REPOSITORY RECORD

Moss, Kate, and Ken Pease. 2019. "Data Sharing in Crime Prevention: Why and How". figshare. https://hdl.handle.net/2134/853. 


\title{
Data Sharing in Crime Prevention: Why and How
}

\begin{abstract}
Kate Moss and Ken Pease ${ }^{1}$
Criteria for the permissible exchange of relevant data within crime and disorder partnerships are to be found in the Crime and Disorder Act 1998. Partnerships have experienced difficulties in reaching agreement about data-sharing. This paper proposes an approach which minimises formal data-sharing while maximising relevance to crime reduction. It should be read as a radical alternative to the approach advocated by Brookes et al (2003) and is based on the excellent work undertaken in the Government Office, East Midlands.
\end{abstract}

\section{Key Words: Data-sharing; crime reduction; partnerships}

\section{Introduction}

In their paper on data-sharing, Brookes et al (2003) describe a painstaking initiative to realise optimal data-sharing within crime reduction partnerships. May success attend these efforts. The present paper offers a different perspective on data-sharing issues, to be considered in the event either:

- that the problem remains intractable, despite the best efforts of the Government Office, East Midlands, and like-minded practitioners and scholars; or

- that the advantages which attend the alternative approach are deemed important enough to be pursued in their own right.

Although the directions taken diverge, the starting point of this paper is shared with that of Brookes et al (2003), namely that police data protection officers vary massively in the presumptions they bring to the work, and in their consequent readiness to share data; senior police officers do not take an active role in shaping agreements on data-sharing; and community safety organisers are often unclear about the action implications of shared data, hence feeding the presumption against data exchange.

A debacle centring upon data exchange between police forces recently enabled Ian Huntley to be appointed to a post as caretaker at Soham College, which in turn made possible the murders of Holly Wells and Jessica Chapman. Cleveland Police's contention that the Data Protection Act required the destruction of information about Huntley led to a currently on-going investigation of the Act and its interpretation. Such scrutiny may lead to the approach taken here becoming unnecessary as an enabler of data-sharing. The authors hope it does. However, the approach would retain some intrinsic virtues in focusing attention on the communication of crime risk and the case-by-case allocation of responsibility for its reduction. 
As emphasised by Brookes et al (2003) individual-level data are necessary to inform the crime reduction enterprise because much crime risk is conferred by personal or household characteristics, alone or interacting with their community contexts (see Tseloni et al, 2004). The unasked question tends to be: what does a partner agency need to know about data other partners hold, while optimising collective action against crime? The argument will be developed with a mindset centred on situational crime prevention directed against burglary, because the present authors believe that most short-term crime reduction benefits in respect of that crime will accrue from the adoption of situational measures (particularly given the Lord Chief Justice's recent guideline sentencing proposals for domestic burglary, which reduce the contribution of enforcement to burglary reduction). However, the same approach could equally apply to circumstances where the unit of analysis is not the person or place at risk of victimisation, but the person at risk of (or embarked upon) a criminal career.

\section{What is crime prevention about?}

At what point should aspiring crime preventers seek to mobilise resources? The answer is surely when the indicators of crime hazard reach a threshold value. ${ }^{2}$ Determinants of hazard are diverse; some are most readily knowable by the police, others by their partners in crime reduction. Table 1 illustrates the point through Tracey Budd's (1999) work. It shows the relative risks conferred by different demographic, location and lifestyle factors. The risks are presented as ratios to 1 , that being the national average risk. As asserted above, different risk factors will be best known to different agencies, and in some cases known imperfectly, if at all, by any. Add the strongest predictive factor-having suffered a previous burglary (see Farrell and Pease, 2001) — and we have the basis of a fine burglary risk assessment instrument. How can we use it so as to minimise data exchange but to optimise collective action? A formula is needed to which even the most privacy-focused data protection officer may adhere. However, the approach is not intended as a 'second-best' alternative to data-sharing as conventionally achieved. Having established an adequate risk assessment instrument to which several partners need to contribute, let us pause to consider an everyday story of data-sharing folk.

\section{Table I. Risks of domestic burglary by household type}

\begin{tabular}{lc}
\hline Household is... & Relative risk \\
\hline Head of household 16-24 & 2.71 \\
One adult living with children & 2.00 \\
Head of household is single & 1.73 \\
Head of household is separated & 1.63 \\
Respondent is Asian & 1.77 \\
Head of household is unemployed & 1.80 \\
Head of household is economically inactive & 1.70 \\
Home is privately rented & 1.73 \\
Respondent resident for less than one year & 1.75 \\
Home has no security measures & 2.71 \\
Home in inner city & 1.52 \\
Home in an area with high levels of physical disorder & 2.14 \\
\hline
\end{tabular}

Note: calculated from Budd 1999 
The request for data typically comes from a community safety officer and is directed primarily at the police. This is in itself interesting, but space precludes discussion of the implications of this pattern, and the fact that (whatever the legal niceties) acceding to the request is in fact a kind of rite of passage of the community safety officer into the role of police confidant(e). There seem to be three common types of reason for the request:

- $\quad$ to inform the allocation of resources already available;

- $\quad$ to provide the material wherewith to lobby for additional resources for particular purposes; and

- $\quad$ to satisfy the requirements of the three-yearly crime audit imposed by the Crime and Disorder Act 1998 (CDA), and to aid the formulation of defensible crime reduction targets.

The point of acute concern to the present authors is that none of these reasons necessarily translates itself into case by case deployment of resources. In the climate reflected in the CDA, it is almost heretical to question the value of routine data exchange for any of the justifications identified. Nonetheless it must be done, for three reasons:

- $\quad$ some data protection officers remain to be convinced about data-sharing; failing to address their concerns directly condemns us to a stand-off which is in no-one's interests;

- $\quad$ compromising privacy for the sake of an agreed social good can be the first step on a very dangerous road; and

- $\quad$ arrangements restricted to the exchange of aggregate data make the deployment of resources far more approximate than the evidence allows; in particular, it makes one vulnerable to the ecological fallacy.

The first of these three reasons is self-explanatory. The second and third require some elaboration.

As for compromising privacy, let us take an apparently uncontentious element of data-sharing. We know that tenure type is associated with burglary risk (see eg Budd, 1999). Therefore, the presumption goes, a database of households by tenure type should be made available by a local authority to the police to inform patrolling priorities and the provision of crime reduction advice. We know that people who are about to move or have just moved home are at higher risk of burglary than others (Ellingworth and Pease, 1998). Therefore, a local authority (preferably in collaboration with estate agents contributing data about the private sector) should provide information to the police about recent and imminent movers, again to inform patrolling priorities and the provision of crime reduction advice. We know that prior victimisation is an excellent predictor of future victimisation, so information from the police to a local authority about recent crimes could be used to expedite repairs and security up-grading of the homes of its burgled tenants. Two features distinguish these examples:

- they are all defensible in that the action which flows from them is based upon risk differentiation supported by extensive research; and

- in each case the informed agency comes to know more than it needs to know-in each case it only needs to know those homes to which it ought to direct attention and effort.

That an agency should know more than it needs to for the purposes of crime prevention is no disaster so long as two conditions apply. The first is that the transmitted information is demonstrably relevant to crime reduction, narrowly conceived, and the second is that it is not pejorative in 
itself, or does not become pejorative when the crime risk is revealed. Problems occur when these conditions are not satisfied. For example, perpetrators of crime are more often burgled (Costello, 2002). Does this mean that criminal records should be visible as a factor in the deployment of crime prevention resources? It is thus concluded that, as a general principle, partners should know the risk of crime to individual people and places with the greatest possible precision, but as few of the factors on which that assessment is based as is practicable.

Turning to the unnecessary crudeness (and potentially positively misleading nature) of aggregate data, the reader is reminded of the ecological fallacy, whereby group differences are erroneously interpreted as operating at the individual level. In the classic Durkheimian example, Christian communities with higher proportions of Protestant citizens also had higher rates of suicide. This can, by the ecological fallacy, be read as meaning that individual Protestants are more likely to kill themselves than individual Catholics. This does not follow. It could equally be that, to the extent that Protestants are in the majority, they become unpleasant to Catholics, who then kill themselves. One social variable whose relationship to crime seems to be unquestioned is deprivation. In fact the link is more complex than one might suppose, with the link working in different directions at the area and individual levels, so that (for example) richer homes in worse areas are those most victimised (Ellingworth et al, 1997). Yet the ecological fallacy would induce the crime preventer wrongly to deploy resources to the poorest homes in the poorest areas. Even at the area level, unpublished work by Machi Tseloni suggests that the link between area deprivation and crime is sufficiently tenuous that the practice of allocating crime reduction money to areas on the basis of their deprivation level is seriously flawed and inefficient. Data-sharing which seeks to provide crime reduction partnerships with information about social deprivation, as a basis for the allocation of crime reduction effort, thus fails both tests. At its worst, data-sharing which assumes the link between poverty and crime can be a kind of ideological shroud-waving, where the information chosen to be shared reflects pre-existing ideologies about crime causation rather than an evidence-led schedule for action. Unless deprivation is regarded as directly and simply criminogenic (against which contention the evidence is strong) any allocation of resources based upon such shared information is inappropriate. Further, designation as a deprived area is pejorative, so to the insult of inappropriate policing levels is added the injury of area-labelling. The real tragedy of such misallocation of resources is their denial to people at individually high risk in areas of low risk in the aggregate, and to people whose areal risk is high because of factors other than those linked to deprivation (eg possibly student areas containing high numbers of homes in multiple occupancy).

To reprise, it is contended that information which should be available across agencies is essentially information about research-estimated risk to individual people, households and locations, but not the components of that risk. Information about prior victimisation, lone-parent status and recent criminal history, all demonstrated by research to elevate crime risk, should be combined into a single risk index whose contributing components remain invisible to each user. If this is a desirable outcome, how might it be achieved?

\section{Crime reduction and blind trusts}

The blind trust is a device whereby a minister avoids accusations of framing policy on the grounds of self-interest. The minister places all his/her investments (including derivatives) into a 'blind' trust, ie one in which the minister is not informed of changes in investments or of the state of the portfolio, but remains entitled to both the capital and income generated. The blind trust is an imperfect measure (for example in the short term a minister will remain aware of his portfolio, and could shape policy on the grounds of self-interest). The principles of the blind trust could inform data-sharing of the kind advocated here. Each local agency would be assigned a set of factors about which that particular agency was best-placed to be informed: the police about 
criminal record and victimisation history; the local authority housing department about housing tenure, movement into and out of homes, secured-by-design status of a dwelling; and so on. These factors would be assessed at individual or household level, as appropriate. The factors would be combined automatically and the elements deleted, with the resulting risk assessment displayed to all partners, who would thus be informed about the fact of high risk without any personal information. The fact of high risk must then be translated into prompt action. How? We have referred to it above as a schedule of contingent actions. Each agency will know how much of the risk is conferred by factors over which it has stewardship. For example, the housing department will know tenure and recency of move to an area. Partnership action would be triggered by the identification of a home or person at high risk. Each participating agency would know which of 'its' factors contributed to the total risk, and the total risk attending a household, but not what the components of that risk were, beyond those conferred by variables within its own domain. There should then be an agreed joint plan of action, in respect of (say) the five per cent of individuals and households standing at greatest risk. Thus practical actions can be agreed in respect of those most at risk to provide a focus which partnership working so often lacks. Refinements to the approach can allow any agency to specify people or households for immediate attention. A further refinement might be the development of the risk assessment scale by the periodic assessment of the predictive power of the scale. The arrangements for this (with a local university as trusted third party, for example) would be for negotiation.

The advantages of the 'schedule of contingent action' approach are as follows:

- no agency would know the reasons for elevated risk other than those derived from its own data;

- $\quad$ aggregate risk assessments would flow from data weighted by the research evidence, not by the power of the participating agencies;

- $\quad$ social theory masquerading as crime risk assessments would be excluded;

- $\quad$ the process would add focus to partnership meetings; and

- the risk assessment could be refined with time, a dynamic not guaranteed by conventional data-sharing.

What are the shortcomings of this approach? There are two. The first is that, since only an agency itself knows what it contributes to crime risk, expedient silence in partnership meetings may lead it successfully to evade its proper share of responsibility. The second is that it omits efforts to find previously unrecognised risk factors. As for the first problem, there are obvious remedies which could be brought to bear if the difficulties loomed large. For example, the risk scale could rank the contribution according to the risk of different agency factors, so as to provide an indication of where the responsibility for change primarily lies. As for the second, it is not really a problemit is difficult to conceive of circumstances in which research to identify new risk factors could be carried out competently within the scope of time and resources available to local partnerships. As it is, much money is wasted on small-scale, methodologically inadequate analyses which could be better done by secondary analysis of the British Crime Survey or other large data sets.

What next?

In the event that the approach to data-sharing advocated in this paper excites interest, the next step would be to present extant data as a risk assessment tool. This should be based on data combination procedures which are transparent to users. This done, and if promising (as it should be), the next step would be a local trial of the IT reality of the approach. 
The authors, in collaboration with the relevant agencies, have identified two residential areas in Nottingham for a pilot study which will produce a risk index along the lines of that described in this paper. The Nottingham BRIx (burglary risk index) is, we think, the first of its kind and is being supported by the Government Office for the East Midlands, by the Nottingham Burglary Reduction Team and by Nottingham police and city council. A data-sharing protocol to facilitate this has also been drawn up.

\section{Notes}

1

Kate Moss is Lecturer in Criminology, Department of Social Sciences, Loughborough University; email: K.R.Moss@lboro.ac.uk. Ken Pease is Visiting Professor, Jill Dando Institute of Crime Science, University College London.

2 Alternatively, effort should be directly geared to hazard, however low the presenting hazard. This approach is probably impractical.

\section{References}

Brookes, S.M., Moss, K. and Pease, K. (2003) Data Sharing and Crime Prevention: The Long and Winding Road. Crime Prevention and Community Safety:An International Journal. Vol. 5, No. 4, pp 7-14.

Budd, T. (1999) Burglary of Domestic Dwellings: Findings from the British Crime Survey. Statistical Bulletin No. 4/99. London: Home Office.

Costello, A. (2002) Patterns of Crime in Sheffield: 1966-2000. Unpublished PhD thesis, University of Sheffield.

Ellingworth, D. and Pease, K. (1998) Movers and Breakers: Household Property Crime Against Those Moving Home. International Journal of Risk, Security and Crime Prevention. Vol. 3, No. 1, pp 35-42.

Ellingworth, D., Tseloni, A. and Pease K. (1997) Prior Victimisation and Crime Risk. International Journal of Risk, Security and Crime Prevention. Vol. 2, No. 3, pp 201-14

Farrell, G. and Pease, K. (2001) Repeat Victimization. Monsey, NY: Criminal Justice Press.

Tseloni, A., Wittebrood, K., Farrell, G. and Pease K. (2004) Burglary Victimisation in England and Wales, the United States and the Netherlands: A Cross-national Comparative Test of Routine Activities and Lifestyle Theories. British Journal of Criminology. Vol. 44, No. 1, pp 66-91. 